\title{
RUSSIA'S ECONOMY IN MARCH 2013: PRELIMINARY DATA AND MAJOR TRENDS
}

\author{
K.Rogov
}

\section{Political Background: No Thaw Yet}

Russia's political background in March appeared to be calm enough. Over recent months, the opposition's activity has been evidently on the decline; the trend displayed by Vladimir Putin' approval ratings, although still downward, is moving at a very slow rate; the deterioration, last autumn, of the general outlook of the current situation as reflected by opinion polls, early this year was no more visible. Meanwhile, the authorities stick to their policy of progressively 'tightening the screws' on political activists and civil organizations. In March, charges were brought against Yelena Kokhtareva, a pensioner, who became the 25th accused person in the so-called Bolotnaya square case. Besides, the police search the homes of political activists in Novosibirsk and St. Petersburg (while some of them had not even been in Moscow on 6 May 2012). And finally, in late March, the law enforcement agencies launched a series of checks of civil-society and human rights organizations, including Human Rights Watch, Amnesty International, and Memorial. In this connection, officials in the USA, the UK and Germany expressed their concerns with the political pressure on independent civil-society organizations in Russia.

In March 2013, the RF State Duma adopted the first reading of a draft law amending Russia's parliamentary election procedures. As was the case with gubernatorial elections, by doing so the Kremlin, in fact, returns to the model that existed prior to 2003: half of the parliament's seats will be subject to direct elections, and the other half will be put to party voting; the election threshold for party representation is to be lowered to $5 \%$. The reestablishment of the 'old order' is a sign that the Kremlin has lost any hope for a revival, in the nearest future, of United Russia's former popularity, and consequently the successful realization of its project of establishing an institutionalized authoritarian regime supported by a ruling party. The 'new old model' with strengthen the positions of the regional elites, enabling them to rather easier get their representatives into the State Duma - who will then be able to get rewarded for their support of the 'party in power' on relevant political issues by that party's benevolent 'understanding' of their specific or regional interests.

The Draft Law introduces a constitutionally dubious norm establishing a new electoral barrier in the form of a life-long ban on persons convicted of serious or exceptionally serious crimes (for a prison term of more than 5 years) standing for parliament. Thus the Kremlin expects to close access to public politics for some of the most charismatic and popular opposition figures. Besides, the Draft Law introduces new restrictions for election observers, who are now deprived of the right to make video recordings at polling stations. In this connection it the reader should be reminded of the new technology of falsification that became widespread during the December 2011 election, when fraudulent data (that differed drastically from those entered in the protocols of the corresponding election commissions verified by the commissions' members and observers) were fed into the State Automated System of the Russian Federation GAS-Vybory. It was the publication of the photographs of the genuine protocols in the Internet (when it was impossible to prove the fact of data falsification in a court) that helped reveal the frauds and thus stirred strong public resonance.

All these maneuvers in the political sphere are indicative of the orientation of Russia's leadership to a scenario of holding on to the power in a situation when the existing political regime will have to put up with only some tepid support in society - in fact, very different from what it had enjoyed in the 2000s.

The nomination of Elvira Nabiullina as head of the RF Central Bank may be interpreted as a rather clear sign on the part of the government. The appointment to this post of a former minister of economic affairs (whose most recent job was that of the President's economic adviser) instead of a financer points to its choice of a moderately expansionary monetary policy. On the one hand, the economic authorities evidently see no other method of boosting economic growth, while on the other they are well aware of the risks of such a maneuver and of excessive softening. The transfer 
to the Bank of Russia of the functions of a financial market regulator implies that government representatives are going to join its board of directors which (alongside Nabiullina' nomination) will result in an even closer integration between the RF Government and the RF Central Bank.

\section{Macroeconomic Background: the Economy Is Stable - and Unattractive}

In March, the per barrel price of oil (ICE.Brent) demonstrated slight fluctuations around the level of $\$ 109$. The stability of world oil prices and the visible slowdown in the US dollar's strengthening against the euro determined a relative stability of the exchange rates of Russia's national currency; over March, the ruble to USD exchange rate slightly declined (no more than by 1.5\%), while the ruble to Euro exchange rate demonstrated a rise - with minimum interference in the natural movement of currency exchange rates on the part of the Bank of Russia. As a result, the price of the bi-currency basket climbed from $\mathrm{Rb} 34.86$ to $\mathrm{Rb} 35$.

At the same time, the crisis in Cyprus - probably in conjunction with the downward movement of oil futures and the unfavorable outlooks for growth in Russian industry - had a serious impact on the dynamics of Russia's stock markets, whose indicators in the period from 15 through 26 March plummeted by 5 to $6 \%$ (it should be noted, however, that a decline was also a typical phenomenon for other exchanges operating in the developing markets). The leaders in the depth of decline were the companies in the raw materials and financial sectors. However, towards the month's end, when it had already become evident that the consequences of the Cyprus crisis for the Russian economy manifested themselves only on a rather moderate scale, the market quotations resumed their upward movement.

The inflation rate in March dropped to $0.3 \%$ (against 1\% in January and $0.6 \%$ in February). As a result, the per annum inflation rate dropped to 7\% (against $7.3 \%$ as recorded at the end of February), and the inflation accumulated since the year's beginning amounted to $1.9 \%$. At the same time, the basic inflation rate remained at its February level (0.4\%), while the decline of the Consumer Price Index (CPI) occurred in response to the slowdown in the growth of food prices ( $0.4 \%$ in March against $0.8 \%$ in February) and prices in the services sector $(0.2 \%$ in March against $0.4 \%$ in February). Meanwhile, according to the forecasts released by the RF Ministry of Economic Development, the drop of consumer inflation to the upper margin of its target range $(6 \%)$ may be expected no earlier than Q3 2013. The relevant factor in this connection will be the situation with crops (it should be reminded that the per annum inflation rate has already been staying above its upper target margin for 7 months). The factors moderating the strength of the inflationary pressure will be the continuing decline of domestic demand and the slowdown in the growth of money supply (the per annum growth rate of M2 dropped from 22.3\% as of 1 February 2012 to $13.2 \%$ as of 1 February 2013). At the same time, the markets are looking forward to softening of the monetary policy in the nearest future.

The simultaneous growth, in February, of the volumes of cash in circulation and required reserves caused an expansion of the narrow monetary base by $0.8 \%$. The shrinkage of the excess reserves of commercial banks was halted, and over February their volume rose by $2.3 \%$ - to Rb $992.3 \mathrm{bn}$. The situation on the money market, which in February was very calm, began to deteriorate in March. This change manifests itself, on the one hand, by the increasing volume of banks' outstanding debt against REPO operations (in March, this indicator once again rose to nearly Rb 1.5 trillion), and on the other, by the rise of interbank rates to above 6\% (MosPrime, one of the major indicators of Russia's market, in March amounted to 6.1-6.4\%).

According to the data released by the Bank of Russia, net capital outflow in Q1 2013 amounted to $\$ 25.8 \mathrm{bn}$. Thus, so far there has been no significant slowdown in capital outflow and the resulting trend reversal, long awaited by the RF Central Bank and the RF Ministry of Economic Development. The drop in the outflow volume on Q1 2012 (\$33.6bn) can hardly be regarded as a positive development. At the same time, the Bank of Russia has no intention of revising its forecast annual outflow level of $\$ 10 \mathrm{bn}$.

So, the macroeconomic situation in Russia remains stable thanks to the high oil prices, which ensure her high foreign trade surplus and high positive current account balance (27.9bn in Q1 2013). Meanwhile, Russia still appears to be unattractive for capital (the inflow of foreign investment in 2012 shrank to $7.7 \%$ of GDP against 10.0\% in 2011). Besides, certain problems may arise 
in response to the faster than expected slowdown in the rate of economic growth that occurred in early 2013, which will result in a decline in budget revenues against the very tight expenditure plans. This will make the budget even more sensitive to the fluctuations of oil prices and their current downward movement coupled with shrinking natural gas supplies. Thus, the results of the period of January-February 2013 already demonstrated that federal budget revenue dropped by $2.3 \mathrm{pp}$. of GDP on the first two months of 2012 , which produced a current federal budget deficit of $2.7 \%$ of GDP against the planned annual deficit level of of $0.8 \%$.

\section{The Real Sector of the Economy: Industry Betrayed by Natural Gas and Consumer Credits}

In February 2013, for the first time since early 2009, Russian industry experienced a decline in output. In reality, the formerly noticeable growth rate of industrial production was halted as early as the end of 2011, shortly after it had risen above its record high of March 2008. However, periods of stagnation have already occurred earlier in the course of the economy's post-crisis recovery (in mid-2010 and in December 2010 - January 2011), but every time these gave was to growth surges. An upward trend also became visible in Q2 2012, but it was very weak, and so, from July 2012 through January 2013, industry was effectively stagnating. In February 2013, the industrial production decline in per annum terms amounted to $-2.1 \%$; the Processing Industry Index in per annum terms dropped to $99.9 \%$, that of the mineral resources extraction - to $97.8 \%$, and that of the production of electric energy, gas and water - to $90,0 \%$. Thus, it can be concluded that the February slump was predetermined by the decline in the extracting industry against the backdrop of a warm winter and the stagnation in the processing industry. The most impressive decline was demonstrated by the volumes of natural gas production (-4.7\% on February 2012) and petroleum production, including gas condensate $(-2.2 \%)$.

The low investment demand resulted in a decline in the production of capital goods. In February 2013 , the index of the production of machinery and equipment in per annum terms c amounted to $95.7 \%$, that of the production of electrical, electronic and optical equipment - to $92.6 \%$. After a long period of growth, late 2012 and early 2013 saw a decline in the production of transport vehicles - to $91.8 \%$ of the February 2012 level (while the output of passenger motor cars in January - February amounted to $109.1 \%$ in per annum terms).

In fact, output growth on January-February 2012 persisted only in the chemical industry, the production of rubber and plastic materials, as well as construction materials. A controversial situation emerged in the consumer goods industry. On the one hand, some sectors displayed growth (the textile and dressmaking industry, the production of leather goods and footwear), while on the other, the consumer goods industry on the whole was experiencing pressure from the demand constraints. For eight quarters in a row (from the second half of 2010 to mid-2012), the mean retail turnover growth rate stayed at the level of $7.3 \%$ per annum. In the second half of 2012 , this index dropped to $4.6 \%$, and then in January-February 2013 - to 3.0\%. In fact, the period of growth in trade came to an end four months ago. It is noteworthy that the retail turnover slowdown coincided with the reversal of the trend displayed by consumer credits - their volume became significantly slower in per annum terms.

According to the entrepreneurial activity surveys conducted by Rosstat, the entrepreneurial confidence index in the processing industry (cleared of the seasonal factor) over the period of February-March was improving, while in the processing industry, on the contrary, it was indicative of an increasing pessimism. The data yielded in February by the business opinion surveys carried out by the Gaidar Institute are highly controversial. The evident sales and output growth occurred in face of high surplus finished stocks and the definitely dwindling optimism with regard to the prospects of demand, production and employment. The investment plans demonstrated that the traditional 'new year pause' was finally over, but their balance amounted to zero - that is, industry is planning no investment growth as yet.

Thus, for a period of no less than four months in a row, the Russian economy is experiencing stagnation which, nevertheless, is no obstacle to the continuing income growth, a stable employment rate and a high growth rate of prices. 